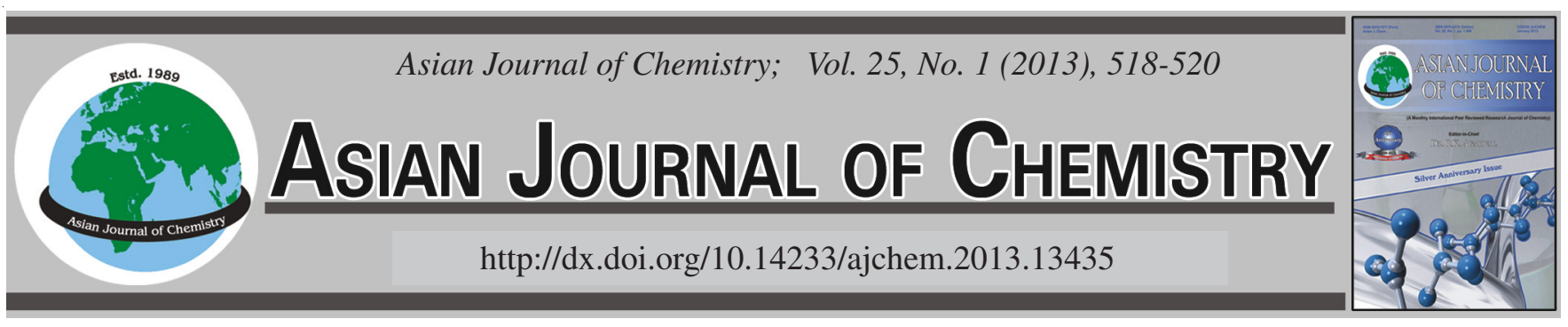

\title{
Synthesis and Characterization of Tridentate Schiff Base Derivative of Indenyl Lanthanoid Chloride Tetrahydrofuranate Complexes for Catalytic Applications
}

\author{
Muhammad YousaF ${ }^{1}$, Ameer Fawad Zahoor ${ }^{1 *}$, Anbreen Anjum ${ }^{2}$, Tanveer Hussain Bokhari ${ }^{1}$, \\ Kulsoom Ghulam Ali ${ }^{1}$, Bushra Purveen ${ }^{1}$, Shazia Naheed ${ }^{1}$, Abdul Jabbar $^{1}$ and Hafiz Badaruddin Ahmad ${ }^{3}$
}

\author{
${ }^{1}$ Department of Chemistry, Government College University, Allama Iqbal Road, Faisalabad, Pakistan \\ ${ }^{2}$ Department of Applied Chemistry, Government College University, Allama Iqbal Road, Faisalabad, Pakistan \\ ${ }^{3}$ Department of Chemistry, Bahauddin Zikeria University, Multan, Pakistan \\ *Corresponding author: E-mail: fawad.zahoor@gmail.com
}

(Received: 12 January 2012;

Accepted: 2 August 2012)

AJC-11915

Four kinds of novel lanthanocene complexes were synthesized in reasonable yield by the reaction of equimolar quantity of sodium salt of tridentate Schiff base [N-(2-methoxyphenyl)salicylideneimine] with indenyl lanthanoid dichloride tetrahydrofuranate in tetrahydrofuran. All the complexes after purification were characterized by MS and EA, respectively. These complexes isomerized successfully the 1,5hexadiene into a mixture of products such as 1,4-hexadiene, 2,4-hexadiene,1,3-hexadiene, methylenecyclopentane and methylcyclopentene. Similarly they also proved effective for the polymerization of methylmethacrylate (MMA), $56.45 \%$ yield and high molecular weight $\left(355 \times 10^{3}\right)$.

Key Words: Indene, Tridentate Shiff base, Lanthanoid complexes.

K -

\section{INTRODUCTION}

The literature survey explains that metal complexes of Schiff bases occupy a central role in coordination chemistry for analytical, physical and biological properties ${ }^{1}$.

A contemporary theme in modern lanthanoid chemistry is the design of new ligand environments of lanthanoid complexes which are capable of saturating the coordination sphere of lanthanoid $\left(\mathrm{Ln}^{3+}\right)$ ions and exhibiting high reactivity. Accordingly Schiff bases have the advantages of ease of synthesis, low cost, a hard donor atom framework and tunable steric and electronic effects.

The recent growth in organolanthanoid chemistry has primarily focused on complexes stabilized by tridentate Schiff base ligand system.Further interest in exploring the metal ion complexes with Schiff base ligands has continueously increased, since it has been recognized that many of Schiff base derivative of lanthanocene complexes may serve as biologically important, naturally occurring ionophores. Literature verifies that lanthanocene hydride complexes are fundamental components in a wide range of stoichiometric and catalytic organometallic reactions ${ }^{2}$. A large number of Schiff bases and their complexes with lanthanoids have been studied for their interesting and important properties, such as, their ability to reversibly bind oxygen $^{3}$, catalytic activity in hydrogenation of olefins ${ }^{4}$, transfer of amino group ${ }^{5}$. Catalytic synthesis of polymethylmethacrylate ${ }^{6}$, isomerization of I, 5-hexadiene into various products ${ }^{7}$ and so on. Similarly a series of Schiff base derivative of lanthanoid complexes with $\beta$-diketone hydrazone derivatives were synthesized which exhibited the antibacterial and antifungal potential activity $^{8}$. A large number of lanthanoid complexes with cyclopentadiene/its substituted products and different types of the Schiff bases such as monodentate, bidentate, tridentate, tetradentate, etc. have exhibited their importance in industrial as well as biological fields. Schiff bases derivative of lanthanoid complexes with indenyl are not so much reported. In this work, new series of tridentate Schiff base derivative of lanthanoid complexes with indenyl ligand have been reported. After characterization, their catalytic potential have been studied for the polymerization of methylmethacrylae and isomerization of 1,5-hexadiene.

\section{EXPERIMENTAL}

Standard schlenk techniques, a vacuum atmospheres and $\mathrm{N}_{2}$ filled glovebox were used through the isolation and handling of metal complexes. All the analytical grade solvents were dried over sodium metal, refluxed and distilled over blue sodium benzophenone under argon immediately before use. Anhydrous $\mathrm{LnCl}_{3}$ and indenyl lanthanoid dichloride tetrahydrofuranate complexes were prepared according to the 
literature method $^{9}$. Tridentate Schiff base, N-(2-methoxyphenyl)salicylideneimine was prepared by the condensation of equimolar quantities of purified salicylaldehyde and anisidine in toluene at room temperature. The resulting Schiff base was purified by recrystallization in petroleum ether, dried and was used to prepare its salt with sodium metal in tetrahydrofuran (THF).

Synthesis of (Ind) $\mathrm{Sm}\left(\mathrm{C}_{14} \mathrm{H}_{13} \mathrm{NO}_{2}\right) \mathrm{Cl} \cdot \mathbf{2 T H F}(\mathbf{1})$ : To a stirring $40 \mathrm{~mL}$ of THF solution of indnyl (Ind) samarium dichloride tetrahydrofuranate ( $8 \mathrm{mmol}$ ) was syringed an equimolar solution of sodium salt of $\mathrm{N}$-(2-methoxyphenyl)-salicylideneimine in THF. After stirring for $16 \mathrm{~h}$ at room temperature, the orange yellow solution was concentrated under reduced pressure in order to get saturated THF solution which was set aside at room temperature for several days. The orange yellow microcrystalline solid was deposited in the bottom which was separated from the solution and after drying yield was calculated to be $48 \%$. m/z (\%): 372.5 (M+-Indenyl-THF-Cl 100), 483.5 $\left(\mathrm{M}^{+}\right.$-Schiff base-THF-Cl 56.5), 115 (indenyl 2.7), 226 (Schiff base 1.5), 72 (THF 2.5) Anal. $\mathrm{C}_{31} \mathrm{H}_{35} \mathrm{NO}_{4} \mathrm{ClSm}$. Calcd: $\mathrm{C}$, 55.48; H, 5.22; N, 2.08. Found: C, 55.52; H, 5.02; N, 2.06.

Synthesis of (Ind) $\mathrm{Eu}\left(\mathrm{C}_{14} \mathrm{H}_{13} \mathrm{NO}_{2}\right) \mathrm{Cl} \cdot 2 \mathrm{THF}$ (2): This compound was prepared analogously to complex $\mathbf{1}$ from the reaction of equimolar indenyl europium dichloride tetrahydrofuranate $(7.5 \mathrm{mmol})$ and sodium salt of $\mathrm{N}-(2-$ methoxyphenyl)salicylideneimie in THF. The yellow micro crystalline solid was obtained in $52 \%$ yield. m/z (\%): 374.5 ( ${ }^{+}$-indenyl-THF-Cl 100), 485.5 ( $\mathrm{M}^{+}$-Schiff base-THF-Cl 55.7), 115 (indenyl 2.5), 226 (Schiff base 1.9) 72 (THF 2.1) Anal. $\mathrm{C}_{31} \mathrm{H}_{35} \mathrm{NO}_{4} \mathrm{ClEu}$. Calcd: C, 55.32; H, 5.20; N, 2.08 Found: C, 55.29; H, 5.21; N, 2.09.

Synthesis of (Ind) $\mathbf{G d}\left(\mathrm{C}_{14} \mathrm{H}_{13} \mathrm{NO}_{2}\right) \mathbf{C l} \cdot \mathbf{2 T H F}$ (3): The complex $\mathbf{3}$ was also synthesized analogously to complex $\mathbf{1}$ by reacting equimolar indenyl-gadoliniumdichloride tetrahydrofuranate $(8.8 \mathrm{mmol})$ with sodium salt of $\mathrm{N}$-(2-methoxyphenyl) salicylideneimine in THF. The deep yellow microcrystalline solid in $49 \%$ yield was obtained. $\mathrm{m} / \mathrm{z}(\%): 379.5\left(\mathrm{M}^{+}\right.$-indenylTHF-Cl 100), 490.5 ( $\mathrm{M}^{+}$-Schiff base-THF-Cl 56.7), 115 (indenyl 2.3), 226 (Schiff base 2.0) 72 (THF 2.5) Anal. $\mathrm{C}_{31} \mathrm{H}_{35} \mathrm{NO}_{4} \mathrm{ClEu}$. Calcd: C, 54.71; H, 5.17; N, 2.07 Found: C, 54.76; H, 5.20; N, 2.09.

Synthesis of (Ind) $\operatorname{Er}\left(\mathrm{C}_{14} \mathrm{H}_{13} \mathrm{NO}_{2}\right) \mathrm{Cl} \cdot 2 \mathrm{THF}$ (4): Similarly this complex was prepared analogously to complex $\mathbf{1}$ from the reaction of equimolar amount of indenylerbiumdichloride tetrahydrofuranate $(6.5 \mathrm{mmol})$ with sodium salt of $\mathrm{N}$-(2methoxyphenyl) salicylideneimine in THF. The Orange yellow microcrystalline solid in $51 \%$ yield was obtained. $\mathrm{m} / \mathrm{z}(\%)$ : 389.5 ( $\mathrm{M}^{+}$-indenyl-THF-Cl 100), 500.5 ( $\mathrm{M}^{+}$-Schiff base-THFCl 55.9), 115 (indenyl 2.5), 226 (Schiff base 2.4) 72 (THF
2.9) Anal. $\mathrm{C}_{31} \mathrm{H}_{35} \mathrm{NO}_{4} \mathrm{ClEu}$. Calcd: C, 54.11; H, 5.09; N, 2.04 Found: C, 54.14; H, 5.12; N, 2.07.

\section{RESULTS AND DISCUSSION}

The synthetic route of all the complexes (1-4) is explained in the Scheme-I.
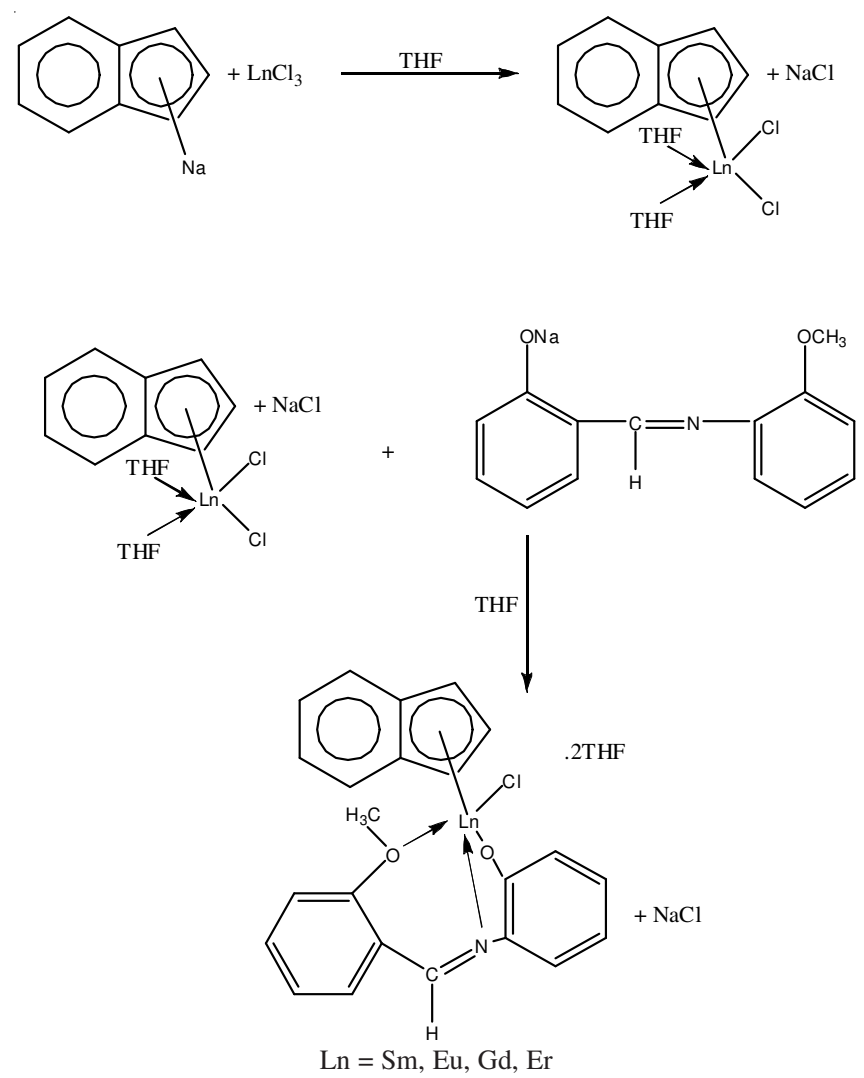

Scheme-I: Synthesis of tridentate Schiff base derivative of indenyl lanthanoid complexes

These complexes along with $\mathrm{NaH}$ successfully isomerized the 1,5-hexadiene (Scheme-II) into various products such as 1,4-headiene, 2,4-hexadiene, methylcyclopentene and methylenecyclopentane Table-1.

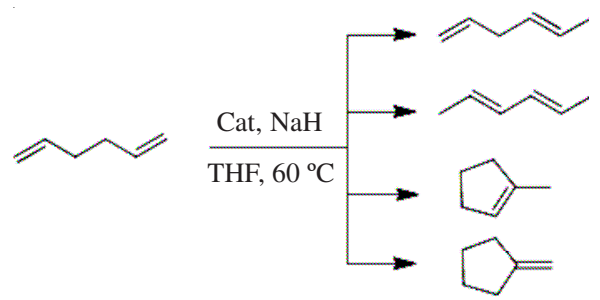

Scheme-II: Isomerization of 1,5-hexadiene in presence of lanthanide complexes

\begin{tabular}{|c|c|c|c|c|c|c|c|}
\hline \multicolumn{8}{|c|}{$\begin{array}{c}\text { TABLE-1 } \\
\text { EFFECT OF CATALYST ON THE ISOMRIZATION OF 1,5-HEXADIENE }\end{array}$} \\
\hline S. No. & Catalyst & $\begin{array}{c}\text { Conversion } \\
(\%)\end{array}$ & $\begin{array}{l}\text { 1,4-Hexadiene } \\
(\%)\end{array}$ & $\begin{array}{l}\text { 2,4-Hexadiene } \\
(\%)\end{array}$ & $\begin{array}{c}\text { Methylene } \\
\text { cyclopentane (\%) }\end{array}$ & $\begin{array}{c}\text { Methyl } \\
\text { cyclopentene (\%) }\end{array}$ & Linear/Cyclic \\
\hline 1 & $\mathrm{C}_{31} \mathrm{H}_{35} \mathrm{NO}_{4} \mathrm{ClSm}$ & 29.2 & 83.5 & 2.5 & 12.8 & 4.9 & $86.0 / 17.7$ \\
\hline 2 & $\mathrm{C}_{31} \mathrm{H}_{35} \mathrm{NO}_{4} \mathrm{ClEu}$ & 25.7 & 80.7 & 2.9 & 12.1 & 4.3 & $83.6 / 16.4$ \\
\hline 3 & $\mathrm{C}_{31} \mathrm{H}_{35} \mathrm{NO}_{4} \mathrm{ClGd}$ & 24.9 & 74.9 & 6.7 & 14.7 & 5.0 & $81.6 / 19.7$ \\
\hline 4 & $\mathrm{C}_{31} \mathrm{H}_{35} \mathrm{NO}_{4} \mathrm{ClEr}$ & 21.4 & 56.5 & 7.5 & 24.6 & 8.5 & $64.0 / 33.1$ \\
\hline 5 & $\mathrm{ErCl}_{3}$ & 0.6 & 40.0 & 20.0 & Traces & Traces & - \\
\hline
\end{tabular}

Reaction conditions: Catalyst/Hexadiene (1:20), Catalyst/NaH (1:50), time $(20 \mathrm{~h})$, temperature $\left(60^{\circ} \mathrm{C}\right)$, solvent $(\mathrm{THF})$. 
The complex 1 expressed better activity than all other attempted ones, which may be due to greater ionic radius of samarium metal than any other metal used (Gd, Eu and Er). It means that greater the ionic radius greater will be the coordination sphere of the metal. Hence, the easier the monomeric unit will make attachment with metal during isomerization.

Similarly these catalysts along with $\mathrm{Al}(\mathrm{i}-\mathrm{bu})_{3}$ yielded high molecular weight $\left(355 \times 10^{3}\right)$ polymethylmethacrylate with narrow polydispersity (1.70) (Table-2). Among all the catalysts the complex 1 exhibited better efficiency than others which again is due to the greater ionic radius of the samarium metal than other used during the formation of complexes (1-4).

TABLE-2

EFFECT OF CATALYSTS ON THE POLYMERIZATION OF METHYLMETHACRYLATE (MMA)

\begin{tabular}{|c|c|c|c|c|}
\hline $\begin{array}{l}\text { S. } \\
\text { No. }\end{array}$ & Catalyst & $\begin{array}{c}\text { Conversion } \\
(\%)\end{array}$ & $\begin{array}{c}\mathrm{M}_{\mathrm{v}} \times \\
10^{3}\end{array}$ & $\begin{array}{c}\mathrm{M}_{\mathrm{w}} / \\
\mathrm{M}_{\mathrm{v}}\end{array}$ \\
\hline 1 & IndenylSmCl$\left(\mathrm{C}_{34} \mathrm{H}_{33} \mathrm{NO}_{2}\right) \cdot 2 \mathrm{THF}$ & 56.45 & 355 & 1.70 \\
\hline 2 & IndenylEuCl$\left(\mathrm{C}_{34} \mathrm{H}_{33} \mathrm{NO}_{2}\right) \cdot 2 \mathrm{THF}$ & 53.70 & 310 & 1.80 \\
\hline 3 & IndenylGdCl$\left(\mathrm{C}_{34} \mathrm{H}_{33} \mathrm{NO}_{2}\right) \cdot 2 \mathrm{THF}$ & 51.45 & 280 & 1.75 \\
\hline 4 & IndenylErCl$\left(\mathrm{C}_{34} \mathrm{H}_{33} \mathrm{NO}_{2}\right) \cdot 2 \mathrm{THF}$ & 40.50 & 195 & 1.83 \\
\hline 5 & $\mathrm{SmCl}_{3} *$ & 9.5 & 13 & - \\
\hline 6 & $\mathrm{Al}(\mathrm{i}-\mathrm{Bu})_{3} *$ & 15.5 & 15 & - \\
\hline
\end{tabular}

\section{ACKNOWLEDGEMENTS}

Financial Support from the University Research Fund (URF) of Government College University, Faisalabad, Pakistan is highly acklowledged.

\section{REFERENCES}

1. K. Desai and B.T. Thaker, J. Indian Chem. Soc., 67, 667 (1990).

2. R.G. Teller and R. Bau, Structural Bonding, Berlin Spriger Press, Berlin, Germany, end. 1. pp. 44-60 (1981).

3. R.D. Jones, D.A. Summerville and F. Basolo, Chem. Rev., 79, 139 (1979).

4. G. Hinrici-Olie and S. Olive, The Chemistry of Catalysed Hydrogenation of Carbon Monoxide, Berlin Springer Press, Berlin, Germany, p. 152 (1984).

5. H. Dugas and C. Penny, Bioorganic Chemistry, Springer Press, New York, USA, edn. 5, pp. 435-475 (1981).

6. M. Yousaf, J. Huang, F.Z. Feng, Y. Qian, S.J. Quan and P. Zhida, Chin. J. Chem., 18, 779 (2000).

7. M. Yousaf, G.A. Kulsoom, B. Bushra, A. Jabbar, H.B. Ahmad and H. Ma, Asian J. Chem., 22, 5254 (2010).

8. W.H. Hegazy and I.H. Al-Motawaa, Bioinorg. Chem. Appl., 2011, 1 (2011).

9. M. Yousaf, L. Qian-Cai, J. Huang and Y.L. Qian, Chin. J. Chem., 18, 740 (2000). 